\title{
The Impact of Social Support, Unit Cohesion, and Trait Resilience on PTSD in Treatment- Seeking Military Personnel with PTSD: The Role of Posttraumatic Cognitions
}

\section{Introduction}

The prevalence of posttraumatic stress disorder (PTSD) in active duty military personnel who have deployed in support of Operations Enduring Freedom (OEF) and Iraqi Freedom (OIF), is estimated to be between 5\% and 17\% (Gates et al., 2012; Hoge et al., 2004; Milliken et al., 2007; Richardson et al., 2010). Prior research examining predictors of PTSD have identified several psychosocial factors that are thought to mitigate PTSD severity in military personnel, including social support, unit cohesion, and resilience.

The protective effect of social support on PTSD has long been recognized (Charuvastra and Cloitre, 2008). Meta-analyses have found that greater perceived social support is strongly related to lower PTSD symptom severity among military personnel (Brewin et al., 2000; Ozer et al., 2003). A similar but distinct construct is unit cohesion, which is the sense of unity a service members feel in terms of interpersonal relationships and task orientation with other members in their unit (Oliver et al., 2000). Unit cohesion has been associated with lower PTSD severity among Marines returning from Iraq (Armistead-Jehle et al., 2011) and among Air Force medical personnel, even when controlling for trauma exposure (Dickstein et al., 2010). Similarly, trait resilience has also been associated with lower PTSD severity among soldiers returning from OEF/OIF (Pietrzak et al., 2009, 2010). Trait resilience is a multidimensional construct which is conceptually distinct from "no-psychopathology". It encompasses behaviors, ways of thinking, and emotional reactions that support positive adaptions to challenging and stressful situations (Agaibi and Wilson, 2005). In the context of war-related trauma, military personnel with greater trait resilience would be those who are more able to maximize internal resources (e.g., hardiness 
and self-esteem) and external resources (e.g., social support and unit cohesion) to mitigate the negative impact of adversities (Duan et al., 2015).

How these factors might mitigate PTSD severity is not well understood, as few prior studies have tested hypothesized mediators between single psychosocial factors and PTSD severity. One possible mediator is negative posttraumatic cognitions. Posttraumatic cognitions (e.g., Foa et al., 1999), which include negative cognitions about the self (e.g., I'm incompetent), negative cognitions about the world (e.g., the world is a dangerous place, no one can be trusted), and self-blame (e.g., the event [trauma] happened because of the sort of person I am) have been consistently related to PTSD severity (e.g. Ehlers et al., 2012; Mueser et al., 2008; Zalta et al., 2014; Zoellner et al., 2011), and reductions in posttraumatic cognitions have been associated with reductions in PTSD symptoms (Foa and Rauch, 2004; Moser et al., 2007). Moreover, there is reason to hypothesize that psychosocial factors such as social support, unit cohesion, and trait resilience would be related to lower negative posttraumatic cognitions. Specifically, several theorists have posited that high social support may reduce the risk for the development and persistence of negative posttraumatic cognitions by influencing victims' attributions about traumatic events (Ehlers and Clark, 2000; Guay et al., 2006). Indeed, two studies have tested posttraumatic cognitions as a mediator of the relationship between social support and PTSD with cross-sectional data. One study with victims of intimate partner violence and motor vehicle accidents found that support from family and friends was negatively correlated with posttraumatic cognitions, which in turn were positively associated with PTSD (Woodward et al., 2015). Similarly, research among mixed trauma survivors found that the relationship between PTSD and social constrains (negative/unsupportive social interaction) was partially mediated by posttraumatic cognitions (Belsher et al., 2012). In a longitudinal study among civilian survivors 
of serious motor vehicle accidents, it is found that when controlling for posttraumatic cognitions, the longitudinal relationship between social support and PTSD severity became nonsignificant (Robinaugh et al., 2011). Psychological resilience has also been theorized to decrease negative cognitions by enhancing self-efficacy and control (Bonanno, 2004). In a nonclinical sample of undergraduate students, higher trait resilience was significantly related to more positive global cognitions about the self, the world, and the future (Mak et al., 2011). Although, to our knowledge, no prior study has investigated the relationship between unit cohesion and posttraumatic cognitions, we hypothesize that unit cohesion may also be related to posttraumatic cognitions, as high-level unit cohesion may enhance confidence in unit members and thus reduce negative cognitions (e.g. self-blame).

Based on the theory (e.g., Ehlers and Clark, 2000) and previous empirical research (e.g., Dickstein et al., 2010; Foa and Rauch, 2004; Pietrzak et al., 2009, 2010) noted above, we hypothesized that posttraumatic cognitions would mediate the relationship of social support, unit cohesion and trait resilience on PTSD. We also hypothesized that social support, unit cohesion, and trait resilience would be interrelated, and that these three factors reflect a single metaconstruct, which we termed "personal resources." This hypothesis was based on research showing that resilience and social support work in concert with one another in the context of trauma. Specifically, previous studies have found that United States Army personnel with greater resilience tend to be more skilled at developing social networks and seeking social support in times of need than those with less resilience (King et al., 1998; Sharkansky et al., 2000). Conversely, developmental research with civilians has shown that individuals living in supportive environments tend to have higher levels of resilience (National Scientific Council on the Developing Child, 2010). The hypothesis that social support, unit cohesion and trait 
resilience will form a latent construct recognizes that individuals are embedded in social systems (e.g., soldiers embedded in their unit), and that these systems likely support the adaptive psychological capacities of the individual.

Using cross-sectional baseline data from a large randomized clinical trial, we examined the associations between personal resources, posttraumatic cognitions, and PTSD severity among active duty military personnel seeking treatment for PTSD. As shown in Figure 1, we hypothesized that: (1) social support, unit cohesion, and psychological resilience will all be the indicators of a robust latent variable, named personal resources; (2) social support, unit cohesion, and psychological resilience will be negatively associated with PTSD severity; (3) personal resources will be negatively associated with posttraumatic cognitions; (4) posttraumatic cognitions will mediate the association between personal resources and PTSD severity.

\section{Methods}

\subsection{Procedure}

This study utilized baseline data collected as part of a randomized clinical trial evaluating the efficacy of prolonged exposure (Foa et al., 2007) therapy for the treatment of PTSD in active duty military personnel. Following informed consent, eligibility was determined during a baseline evaluation consisting of a clinical interview administered by an independent evaluator and the completion of self-report measures. The institutional review boards of Brooke Army Medical Center, the University of Texas Health Science Center at San Antonio, and the University of Pennsylvania approved the protocol.

\subsection{Participants}

Participants were 366 treatment-seeking post-9/11 active duty military personnel who had returned from deployments to Afghanistan, Iraq, or nearby locations and were diagnosed with PTSD using the PTSD Symptom Scale - Interview Version (PSS-I; Foa et al., 1993), which 
follows the Diagnostic and Statistical Manual of Mental Disorders (4th ed., text rev.; DSM-IV$T R$, American Psychiatric Association, 2000). Inclusion criteria were: (1) adult (ages 18-65) male and female active duty military personnel, activated Reservist, or activated National Guard seeking outpatient treatment for PTSD; (2) diagnosis of PTSD as determined by the PSS-I; (3) exposure to a $D S M-I V$ Criterion A traumatic event that was a specific combat-related event or high magnitude operational experience that occurred during a military deployment in support of OEF, OIF, or Operation New Dawn. Exclusion criteria were: (1) current bipolar disorder or psychotic disorder; (2) current alcohol dependence; (3) moderate or severe traumatic brain injury; (4) current suicidal ideation severe enough to warrant immediate attention; and (5) other disorders severe enough to warrant immediate treatment.

The majority of the sample were men (88.0\%), and the average age was 32.73 years ( $S D$ =7.34). Participants identified as White (61.2\%), Black (23.5\%), Asian (0.8\%), and other racial backgrounds (14.5\%); 80.6\% identified as Non-Hispanic. The PSS-I mean score $(M=25.47, S D$ =6.39) indicated that the participants had moderate PTSD symptoms (see Table 1). The RSES mean score $(M=51.3, S D=16.10)$ indicated "moderate resilience" of the participants (Johnson et al., 2008). Meaningful variability on resilience was also showed that $44.5 \%$ of the participants had "low resilience" $(M=0-49)$ and $12 \%$ had "high resilience" $(M=71-88)$.

\subsection{Measures}

PTSD Symptom Scale - Interview Version (PSS-I). The PSS-I (Foa et al., 1993) is a 20-minute, 17-item clinician-administered interview that evaluates DSM-IV PTSD symptoms on frequency and severity. Items are rated on a 4 -point scale $(0=$ not at all to $3=$ very $m u c h)$. The PSS-I has excellent test-retest reliability (.80) and inter-rater reliability (kappa $=.91$; Foa and Tolin, 2000). The PSS-I is comparable to the gold standard employed in studies of veterans (the Clinician Administered PTSD Scale; CAPS; Weathers et al., 1999), yet takes less time to 
administer (Foa and Tolin, 2000) and is considered a common data element for PTSD research (Kaloupek et al., 2010). The Cronbach's alpha for the PSS-I in the current sample was .67.

Interpersonal Support Evaluation List - 12 (ISEL-12). The ISEL-12 (Cohen and Hoberman, 1983) is a 12-item self-report measure of perceived social support in general. The ISEL consists of three subscales: Appraisal (e.g., there is someone I can turn to for advice about handing problems with my family), Belonging (e.g., if I wanted to have lunch with someone, I could easily find someone to join me), and Tangible (e.g., if I were sick, I could easily find someone to help me with my daily chores). Items are rated on a 4-point scale $(1=$ definitely false to $4=$ definitely true). The measure has been shown to have strong psychometric properties (Cohen et al., 1985). The Cronbach's alpha for the ISEL in the current sample was .87.

\section{The Walter Reed Army Institute of Research (WRAIR) Military Vertical \&}

Horizontal Cohesion Scales. The WRAIR is used to evaluate attitudes about support from leaders (vertical) and peers (horizontal) in the military. These scales were developed by researchers at WRAIR to assess military-specific social cohesion. The horizontal cohesion scale was a three-item cohesion scale with a Cronbach's alpha of .86 to .88 (Podsakoff and MacKenzie, 1994). Items assess the degree to which service members believe that they can cooperate with and depend upon, and stand up for one another. Items on this scale are rated from 1 (Strongly Disagree) to 5 (Strongly Agree). The vertical cohesion scale was derived from the unit manning study (see Vaitkus, 1994) using items with an inter-item correlation greater than .50 (Vaitkus, 1994). Items on this scale are rated from 1 (Never) to 5 (Always). Participants were asked to complete this measure in relation to the unit they were currently assigned to, rather than assigned to previously. The Cronbach's alpha for the WRAIR in the current sample was .94. 


\section{The Response to Stressful Experiences Scale (RSES) (previously known as the}

national center for PTSD trait resilience scale). The RSES (Johnson et al., 2011) is a 22-item self-report scale that measures trait resilience following a stressful event. Factor analysis (Johnson et al., 2011) has identified 5 factors including meaning-making and restoration (e.g., learning important and useful life-lessons), active coping (e.g., taking action), cognitive flexibility (e.g., looking at a problem number of ways), spirituality (e.g., leaning on faith in God), and self-efficacy (e.g., expecting that one can handle adversity). Participants are asked to rate whether each item is 0 (not at all like me) to 4 (exactly like me). This scale provides a total resilience score by summing all 22 items. Psychometrically, the RSES has shown good test-retest reliability (.87) and high correlations with other measures of resilience (coefficient alpha of .61 to .81). The Cronbach's alpha for the RSES in the current sample was .92.

The Posttraumatic Cognitions Inventory (PTCI). The PTCI (Foa et al., 1999) is a 36item self-report questionnaire of negative trauma-related thoughts and beliefs. The measure consists of three subscales: negative cognitions about the self, negative cognitions about the world, and self-blame. The PTCI has demonstrated good test-retest reliability, discriminant validity, and convergent validity with measures of PTSD severity, anxiety, and depression (Beck et al., 2004; Foa et al., 1999). The Cronbach's alpha for the PTCI in the current sample was .95.

\subsection{Data Analyses}

The hypothesized model (see Figure 1) was tested via structural equation modeling (SEM). SEM was selected because it can investigate latent variables with multiple indicators (Holmbeck, 1997), which minimizes the effects of measurement error and generates fit statistics to determine the adequacy of the model (Ullman and Bentler, 2003). After confirming that the data did not violate the assumption of multivariate normality, maximum likelihood method of estimation was applied. 
Hypotheses were analyzed in three steps. The first step of analyses examined the measurement models for the three latent variables. Personal resources (indicated by ISEL, WRAIR, and RSES), posttraumatic cognitions (indicated by the three PTCI subscales), and PTSD (indicated by the three PSS-I subscales) were tested as latent variables. The second step evaluated the direct effect of personal resources on PTSD, using the original and classical approaches described by Baron and Kenny (1986) and Holmbeck (1997). The last step added posttraumatic cognitions into the model to test whether this variable mediated the effects of personal resources on PTSD.

Indirect and direct effects of all the variables on PTSD were calculated. Bootstrapping method (with 1,000 bootstrap samples) was employed to estimate bias-corrected 95\% confidence interval (CI) and confirm the indirect (mediating) effect. Using AMOS 23 software, models were constructed and compared to one another using the following indices of fit: nonsignificant $\chi^{2}$ value (Hu and Bentler, 1999), root mean square error of approximation (RMSEA) < .08 (Bentler

and Bonett, 1980), and comparative fit index (CFI) >.90 (Bentler, 1990). Because the $\chi^{2}$ statistic is sensitive to sample size, the ratio of chi-square to degrees of freedom $\left(\chi^{2} / d f\right)$ was also considered, with values of 2.0 or less considered satisfactory (Newcomb, 1990). Both unstandardized and standardized regression coefficients are reported.

\section{Results}

Pearson's correlations among all variables included in the model are reported in Table 2. Means and standard deviations of all variables are also presented.

\subsection{Measurement Models}

Analysis of the measurement model for personal resources resulted in very good indices of fit, $\chi^{2}(1)=.714, p=.398 ; \chi^{2} / d f=.714 ;$ RMSEA $=.000, \mathrm{CFI}=1.00$. The personal resources variable was significantly represented by all of three indicators (all at $p<.001$ ); with 
standardized coefficients of .572 for social support, .399 for unit cohesion, and .562 for resilience.

The measurement model for posttraumatic cognitions also resulted in very good indices of fit, $\chi^{2}(1)=.049, p=.825 ; \chi^{2} / d f=.049 ; \mathrm{RMSEA}=.000, \mathrm{CFI}=1.00$. The posttraumatic cognitions variable was significantly represented by all of three indicators (all at $p<.001$ ); with standardize coefficients of .996 for negative cognitions about self, .586 for negative cognitions about the world, and .515 for self-blame. Negative cognitions about the self was the best indicator of posttraumatic cognitions, and $99 \%$ percent of what participants report about negative cognitions about themselves reflects their posttraumatic cognitions.

Finally, the measurement model for PTSD also resulted in very good indices of fit, $\chi^{2}(1)$ $=.215, p=.643 ; \chi^{2} / d f=.215 ;$ RMSEA $=.000, \mathrm{CFI}=1.00$. PTSD was significantly represented by all three indicators (all at $p<.001$ ); with standardize coefficients of .490 for re-experiencing, .565 for avoidance, and .656 for arousal.

\subsection{Direct Effects Analyses}

SEM analysis examining the direct effects of personal resources on PTSD indicated that the structural model fit the data well, $\chi^{2}(7)=8.391, p=.299 ; \chi^{2} / d f=1.199 ; \mathrm{RMSEA}=.023$, CFI $=.994$. Personal resources significantly predicted PTSD symptoms $(\beta=-.481, p<.001)$.

The direct effect of personal resources on posttraumatic cognitions also resulted in a very good fit, $\chi^{2}(8)=5.972, p=.650 ; \chi^{2} / d f=746 ; \mathrm{RMSEA}=.000, \mathrm{CFI}=1$, and confirmed the significant relationship between personal resources and posttraumatic cognitions $(\beta=-.746, p<$ $.001)$.

\subsection{Mediation Analyses}

The mediation model provided a good fit to the data, $\chi^{2}(22)=16.344, p=.798 ; \chi^{2} / d f=$ $.743 ; \mathrm{CFI}=1 ; \mathrm{RMSEA}=.000$ (see Figure 1). Standardized and unstandardized regression 
coefficients for this model are summarized in Table 3, and standardized direct and indirect effects are reported in Table 4 with $95 \%$ CI using bootstrap method.

After adding posttraumatic cognitions, personal resources were no longer significantly associated with PTSD severity $(\beta=-.096, p=.591)$, indicating that posttraumatic cognitions fully mediated the relationship between personal resources and PTSD severity. The model explained $34.5 \%$ percent of variance $\left(R^{2}\right)$ for PTSD symptoms.

\section{Discussion}

This is the first study, to our knowledge, that examined the relationship between psychosocial resources (interpersonal support, unit cohesion, and resilience) as a meta-construct called personal resources, and PTSD severity, and the first to examine posttraumatic cognitions as a mediator between these personal resources and PTSD. Consistent with our first hypothesis, the latent construct of personal resources was confirmed by the SEM model, supporting the notion that individual-level factors (i.e., resilience) may function together with larger social factors (i.e., support from family/friends and military unit) when an individual copes with trauma. Similarly, a multidimensional construct, "social fitness," in military context has been proposed to integrate family/friends support and unit/work cohesion (Coulter et al., 2013). The finding that greater personal resources were associated with lower PTSD severity in military personnel seeking treatment for PTSD is consistent with our second hypothesis and prior research (e.g., Brewin et al., 2000; Dickstein et al., 2010; Pietrzak et al., 2010). The negative association between personal resources and posttraumatic cognitions supported our third hypothesis, suggesting that participants with fewer personal resources would report more negative thoughts and views of themselves and the world, as well as more self-blame.

The mediating model supported our fourth hypothesis, that negative posttraumatic cognitions fully mediated the relationship between personal resources and PTSD. This suggests 
that individuals with lower levels of personal resources are more likely to report negative posttraumatic cognitions about the world being dangerous and themselves as being incompetent. They also are more likely to self-blame. All these negative posttraumatic cognitions are associated in turn with higher PTSD.

Negative posttraumatic cognitions are thought to be central to PTSD (Foa et al., 1999). Empirical studies have consistently shown that reductions in posttraumatic cognitions are associated with reductions in PTSD symptoms in treatment (e.g. Foa and Rauch, 2004; Kleim et al., 2013). The current findings extend this literature by linking personal resources with posttraumatic cognitions. As has been hypothesized with social support specifically (Joseph et al., 1997; Tedeschi and Calhoun, 2004), it may be that personal resources bolster individuals’ self-esteem, sense of mastery or competence, and feeling of connectedness, all of which are inconsistent with negative posttraumatic cognitions about the self, the world, and self-blame. This notion is consistent with Ehlers and Clark's (2000) cognitive model of PTSD, which asserts that the actions or inactions of a traumatized individual's social network can greatly influence the probability of negative posttraumatic cognitions such as "nobody cares about me". High levels of unit cohesion potentially lead to collective cognitive reappraisals (e.g. reduced fear-related cognitions) of negative outcomes in unit members (Fontana et al., 1997) and may also enhance self-efficacy and control. In terms of resilience, Bonanno (2004) suggests that some facets of resilience, such as self-esteem and optimism, foster emotional stability, which could protect against the shattering of cognitive beliefs during stressful times. Similarly, Janoff-Bulman and McPherson Frantz (1997) suggest that resilience may increase the perception of a meaningful world by enhancing feelings of trust and safety. 
Several limitations of the current study should be noted. First, the data were crosssectional, which precludes conclusions regarding causation and the direction of relationship among variables. For example, it may be that posttraumatic cognitions impact personal resources by eliciting negative interpretation of social interaction, withdrawal from relationships or decreased resilient ability. Longitudinal studies are needed to test the directionality of the observed effects. Second, the study relied on self-report measures to assess social support, resilience and cognitions, which share method variance with the other variables, and can be influenced by demand characteristics and thus be susceptible to bias. Third, participants were treatment-seeking military personnel with PTSD. As such, the observed patterns may not generalize to other samples, including service members with PTSD who do not seek PTSD treatment. Future studies may benefit from examining these relationships in broader samples. Despite these limitations, the current study has clinical implications, even though additional research is needed to confirm the directionality of the relationships between personal resources, negative trauma-related cognitions, and PTSD. Given that social support, unit cohesion, and trait resilience are all potentially modifiable, they are candidates for interventions with military personnel with PTSD. For example, training programs designed to increase resilience, perceived social support, and unit cohesion may help minimize PTSD symptoms in service members. Because these factors are interrelated, programs that successfully modify any of them should positively impact the others (e.g., programs that strengthen unit cohesion may also improve resilience). In addition, our finding that the relationship between personal resources and PTSD was fully mediated by posttraumatic cognitions suggests that interventions targeting dysfunctional, negative cognitions such as prolonged exposure (Foa et al., 2007) or cognitive processing therapy (Resick and Schnicke, 1992), may be particularly helpful in reducing PTSD 
symptoms in service members with lower personal resources as they are likely to have higher levels of negative thoughts and beliefs than those with greater personal resources. If the directionality of these relationships is confirmed, clinicians treating service members with PTSD may want to consider patients' level of personal resources when developing a treatment plan and assess negative cognitions throughout treatment (e.g., using the PTCI) to promote effective implementation. In conclusion, this study underscores the influence of personal resources on PTSD severity in military personnel seeking treatment for PTSD, and highlights the importance of negative posttraumatic cognitions in understanding the relationship between personal resources and PTSD. 


\section{References}

Agaibi, C.E., Wilson, J.P., 2005. Trauma, PTSD, and resilience: a review of the literature. Trauma Violence Abuse 6, 195-216. doi:10.1177/1524838005277438

American Psychiatric Association, 2000. Diagnostic and Statistical Manual of Mental Disorders, fourth ed., text revision. American Psychiatric Association, Washington, DC.

Armistead-Jehle, P., Johnston, S.L., Wade, N.G., Ecklund, C.J., 2011. Posttraumatic stress in U.S. Marines: the role of unit cohesion and combat exposure. J. Couns. Dev. 89, 81-88. doi:10.1002/j.1556-6678.2011.tb00063.x

Baron, R.M., Kenny, D.A., 1986. The moderator-mediator variable distinction in social psychological research: conceptual, strategic, and statistical considerations. J. Pers. Soc. Psychol. 51, 1173-1182. doi:10.1037//0022-3514.51.6.1173

Beck, J.G., Coffey, S.F., Palyo, S.A., Gudmundsdottir, B., Miller, L.M., Colder, C.R., 2004. Psychometric properties of the Posttraumatic Cognitions Inventory (PTCI): a replication with motor vehicle accident survivors. Psychol. Assess. 16, 289-298. doi:10.1037/10403590.16.3.289

Belsher, B.E., Ruzek, J.I., Bongar, B., Cordova, M.J., 2012. Social constraints, posttraumatic cognitions, and posttraumatic stress disorder in treatment-seeking trauma survivors: evidence for a social-cognitive processing model. Psychol. Trauma. 4, 386-391. doi: $10.1037 / \mathrm{a} 0024362$

Bentler, P.M., 1990. Comparative fit indexes in structural models. Psychol. Bull. 107, 238-46. doi:10.1037//0033-2909.107.2.238

Bentler, P.M., Bonett, D.G., 1980. Significance tests and goodness of fit in the analysis of covariance structures. Psychol. Bull. 88, 588-606. doi:10.1037/0033-2909.88.3.588

Bonanno, G.A., 2004. Loss, trauma, and human resilience: have we underestimated the human 
capacity to thrive after extremely aversive events? Am. Psychol. 59, 20-28. doi:10.1037/1942-9681.S.1.101

Brewin, C.R., Andrews, B., Valentine, J.D., Holloway, R., 2000. Meta-analysis of risk factors for posttraumatic stress disorder in trauma-exposed adults. J. Consult. Clin. Psychol. 68, 748766. doi:10.10371/0022-006X.68.5.748

Charuvastra, A., Cloitre, M., 2008. Social bonds and posttraumatic stress disorder. Annu. Rev. Psychol. 59, 301-328. doi:10.1146/annurev.psych.58.110405.085650

Cohen, S., Hoberman, H.M., 1983. Positive events and social supports as buffers of life change stress. J. Appl. Soc. Psychol. 13, 99-125. doi:10.1111/j.1559-1816.1983.tb02325.x

Cohen, S., Mermelstein, R., Kamarck, T., Hoberman, H.M., 1985. Measuring the functional components of social support, in: Sarason, I.G, Sarason, B.R. (Eds.), Social Support: Theory, Research and Applications. Martinus Nijhoff Publishers, Dordrecht, The Netherlands, pp. 73-94.

Coulter, I., Lester, P., Yarvis, J., 2013. Social fitness. Mil. Med. 175, 88-96. doi:10.7205/MILMED-D-10-00278

Dickstein, B.D., McLean, C.P., Mintz, J., Conoscenti, L.M., Steenkamp, M.M., Benson, T.A., Isler, W.C., Peterson, A.L., Litz, B.T., 2010. Unit cohesion and PTSD symptom severity in Air Force medical personnel. Mil. Med. 175, 482-486. doi:10.7205/MILMED-D-09-00178 Duan, W., Guo, P., Gan, P., 2015. Relationships among Trait Resilience, Virtues, Post-traumatic Stress Disorder, and Post-traumatic Growth. PLoS One. 10, e0125707. doi:10.1371/journal.pone.0125707

Ehlers, A., Clark, D.. M., 2000. A cognitive model of posttraumatic stress disorder. Behav. Res. Ther. 38, 319-345. doi:10.1016/S0005-7967(99)00123-0 
Ehlers, A., Ehring, T., Kleim, B., 2012. Information processing in posttraumatic stress disorder, in: Beck, J.G., Sloan, D.M. (Eds.), The Oxford Handbook of Traumatic Stress Disorders. Oxford University Press, New York, pp. 191-218.

Foa, E.B., Ehlers, A., Clark, D.M., Tolin, D.F., Orsillo, S.M., 1999. The Posttraumatic Cognitions Inventory (PTCI): Development and validation. J. Consult. Clin. Psychol. 72, 879-884. doi:10.1037/0022-006X.72.5.879

Foa, E.B., Hembree, E.A., Rothbaum, B.O., 2007. Prolonged Exposure Therapy for PTSD: Emotional Processing of Traumatic Experiences: Therapist Guide. Oxford University Press, New York.

Foa, E.B., Rauch, S.A.M., 2004. Cognitive changes during prolonged exposure versus prolonged exposure plus cognitive restructuring in female assault survivors with posttraumatic stress disorder. J. Consult. Clin. Psychol. 72, 879-84. doi:10.1037/0022-006X.72.5.879

Foa, E.B., Riggs, D.S., Dancu, C.V, Rothbaum, B.O., 1993. Reliability and validity of a brief instrument for assessing post-traumatic stress disorder. J. Trauma. Stress 6, 459-473. doi:10.1007/BF00974317

Foa, E.B., Tolin, D.F., 2000. Comparison of the PTSD Symptom Scale-Interview Version and the Clinician-Administered PTSD Scale. J. Trauma. Stress 13, 181-191. doi:10.1023/A:1007781909213

Fontana, A., Rosenheck, R., Horvath, T., 1997. Social support and psychopathology in the war zone. J. Nerv. Ment. Dis. 185, 675-681. doi:10.1097/00005053-199711000-00004

Gates, M.A., Holowka, D.W., Vasterling, J.J., Keane, T.M., Marx, B.P., Rosen, R.C., 2012. Posttraumatic stress disorder in veterans and military personnel: epidemiology, screening, and case recognition. Psychol. Serv. 9, 361-82. doi:10.1037/a0027649 
Guay, S., Billette, V., Marchand, A., 2006. Exploring the links between posttraumatic stress disorder and social support: processes and potential research avenues. J. Trauma. Stress 19, 327-338. doi:10.1002/jts.

Hoge, C.W., Castro, C.A., Messer, S.C., McGurk, D., Cotting, D.I., Koffman, R.L., 2004. Combat duty in Iraq and Afghanistan, mental health problems, and barriers to care. N. Engl. J. Med. 351, 13-22. doi:10.1056/NEJMoa040603

Holmbeck, G.N., 1997. Toward terminological, conceptual, and statistical clarity in the study of mediators and moderators: examples from the child-clinical and pediatric psychology literatures. J. Consult. Clin. Psychol. 65, 599-610. doi:10.1037/0022-006x.65.4.599

Hu, L., Bentler, P.M., 1999. Cutoff criteria for fit indexes in covariance structure analysis: conventional criteria versus new alternatives. Struct. Equ. Modeling. 6, 1-55. doi:10.1080/10705519909540118

Janoff-Bulman, R., McPherson Frantz, C., 1997. The impact of trauma on meaning: from meaningless world to meaningful life, in: Power, M.J., Brewin, C.R. (Eds.), The Transformation of Meaning in Psychological Therapies: Integrating Theory and Practice. John Wiley \& Sons, Inc., Hoboken, NJ, pp. 91-106.

Johnson, D.C., Polusny, M.A., Erbes, C.R., King, D., King, L., Litz, B.T., Schnurr, P.P., Friedman, M., Pietrzak, R.H., Southwick, S.M., 2011. Development and initial validation of the response to stressful experiences scale. Mil. Med. 176, 161-169. doi:10.7205/milmed-d$\underline{10-00258}$

Joseph, S.A., Williams, R.M., Yule, W., 1997. Understanding post-traumatic stress: a psychosocial perspective on PTSD and treatment. Wiley, Chichester, England.

Kaloupek, D.G., Chard, K.M., Freed, M.C., Peterson, A.L., Riggs, D.S., Stein, M.B., Tuma, F., 
2010. Common data elements for posttraumatic stress disorder research. Arch. Phys. Med. Rehabil. 91, 1684-91. doi:10.1016/j.apmr.2010.06.032

King, L.A., King, D.W., Fairbank, J.A., Keane, T.M., Adams, G.A., 1998. Resilience-recovery factors in post-traumatic stress disorder among female and male Vietnam veterans: Hardiness, postwar social support, and additional stressful life events. J. Pers. Soc. Psychol. 74, 420-434. doi:10.1037//0022-3514.74.2.420

Kleim, B., Grey, N., Wild, J., Nussbeck, F.W., Stott, R., Hackmann, A., Clark, D.M., Ehlers, A., 2013. Cognitive change predicts symptom reduction with cognitive therapy for posttraumatic stress disorder. J. Consult. Clin. Psychol. 81, 383-393. doi:10.1037/a0031290

Mak, W.W.S., Ng, I.S.W., Wong, C.C.Y., 2011. Resilience: enhancing well-being through the positive cognitive triad. J. Couns. Psychol. 58, 610-617. doi:10.1037/a0025195

Milliken, C.S., Auchterlonie, J.L., Hoge, C.W., 2007. Longitudinal assessment of mental health problems among active and reserve component soldiers returning from the Iraq war. JAMA 298, 2141-8. doi:10.1001/jama.298.18.2141

Moser, J.S., Hajcak, G., Simons, R.F., Foa, E.B., 2007. Posttraumatic stress disorder symptoms in trauma-exposed college students: the role of trauma-related cognitions, gender, and negative affect. J. Anxiety Disord. 21, 1039-1049. doi:10.1016/j.janxdis.2006.10.009

Mueser, K.T., Rosenberg, S.D., Xie, H., Jankowski, M.K., Bolton, E.E., Lu, W., Hamblen, J.L., Rosenberg, H.J., Mchugo, G.J., Wolfe, R., 2008. A randomized controlled trial of cognitivebehavioral treatment for posttraumatic stress disorder in severe mental illness. J. Consult. Clin. Psychol. 76, 259-271. doi:10.1037/0022-006X.76.2.259

National Scientific Council on the Developing Child, 2010. Persistent fear and anxiety can affect young children's learning and development: working paper no. 9. National Scientific 
Council on the Developing Child, Center on the Developing Child at Harvard University, Cambridge, MA. http://www.developingchild.net

Newcomb, M.D.,1990. What structural modeling techniques can tell us about social support, in: Sarason, I.G., Sarason, B.R., \& Pierce, G.R.(Eds.), Social Support: An Interactional View. John Wiley \& Sons, Inc., New York, pp. 26-63.

Oliver, L.W., Harman, J., Hoover, E., Hayes, S.M., Pandhi, N.A., 2000. A quantitative integration of the military cohesion literature. Mil. Psychol. 11, 57-83. doi:10.1207/s15327876mp1101_4

Ozer, E.J., Best, S.R., Lipsey, T.L., Weiss, D.S., 2003. Predictors of posttraumatic stress disorder and symptoms in adults: a meta-analysis. Psychol. Bull. 129, 52-73. doi:10.1037/19429681.S.1.3

Pietrzak, R.H., Johnson, D.C., Goldstein, M.B., Malley, J.C., Rivers, A.J., Morgan, C.A., Southwick, S.M., 2010. Psychosocial buffers of traumatic stress, depressive symptoms, and psychosocial difficulties in veterans of Operations Enduring Freedom and Iraqi Freedom: the role of resilience, unit support, and postdeployment social support. J. Affect. Disord. 120, 188-192. doi:10.1016/j.jad.2009.04.015

Pietrzak, R.H., Johnson, D.C., Goldstein, M.B., Malley, J.C., Southwick, S.M., 2009. Psychological resilience and postdeployment social support protect against traumatic stress and depressive symptoms in soldiers returning from Operations Enduring Freedom and Iraqi Freedom. Depress. Anxiety 26, 745-751. doi:10.1002/da.20558

Podsakoff, P.M., MacKenzie, S.B., 1994. An examination of the psychometric properties and nomological validity of some revised and reduced substitutes for leadership scales. J. Appl. Psychol. 79, 702-713. doi: $10.1037 / 0021-9010.79 .5 .702$ 
Resick, P.A., Schnicke, M.K., 1992. Cognitive processing therapy for sexual assault victims. J. Consult. Clin. Psychol. 60, 748-756. doi:10.1037/0022-006x.60.5.748

Richardson, L.K., Frueh, B.C., Acierno, R., 2010. Prevalence estimates of combat-related posttraumatic stress disorder: critical review. Aust. N. Z. J. Psychiatry 44, 4-19. doi:10.3109/00048670903393597

Robinaugh, D.J., Marques, L., Traeger, L.N., Marks, E.H., Sung, S.C., Beck, J.G., Pollack, M.H., Simon, N.M., 2011. Understanding the relationship of perceived social support to posttrauma cognitions and posttraumatic stress disorder. J. Anxiety Disord. 25, 1072-1078. doi:10.1016/j.janxdis.2011.07.004

Sharkansky, E.J., King, D.W., King, L.A., Wolfe, J., Erickson, D.J., Stokes, L.R., 2000. Coping with Gulf War combat stress: mediating and moderating effects. J. Abnorm. Psychol. 109, 188-197. doi:10.1037/0021-843X.109.2.188

Tedeschi, R.G., Calhoun, L.G., 2004. Posttraumatic growth: conceptual foundations and empirical evidence. Psychol. Inq. 15, 1-18. doi:10.1207/s15327965pli1501_01

Ullman, J.B., Bentler, P.M., 2003. Structural equation modeling, Handbook of Psychology: Research Methods in Psychology. John Wiley \& Sons, Inc., Hoboken, NJ.

Vaitkus, M.A., 1994. Unit Manning System: Human Dimensions Field Evaluation of the COHORT Company Replacement Model. (Report No. WRAIR/TR-94-0017).Washington, DC: Walter Reed Army Institute of Research.

Weathers, F.W., Ruscio, A.M., Keane, T.M., 1999. Psychometric properties of nine scoring rules for the Clinician-Administered Posttraumatic Stress Disorder Scale. Psychol. Assess. 11, 124-133. doi:10.1037/1040-3590.11.2.124

Woodward, M.J., Eddinger, J., Henschel, A.V, Dodson, T.S., Tran, H.N., Beck, J.G., 2015. 
Social support, posttraumatic cognitions, and PTSD: the influence of family, friends, and a close other in an interpersonal and non-interpersonal trauma group. J. Anxiety Disord. 35, 60-67. doi:10.1016/j.janxdis.2015.09.002

Zalta, A.K., Gillihan, S.J., Fisher, A.J., Mintz, J., McLean, C.P., Yehuda, R., Foa, E.B., 2014. Change in negative cognitions associated with PTSD predicts symptom reduction in prolonged exposure. J. Consult. Clin. Psychol. 82, 171-175. doi:10.1037/a0034735

Zoellner, L.A., Feeny, N.C., Eftekhari, A., Foa, E.B., 2011. Changes in negative beliefs following three brief programs for facilitating recovery after assault. Depress. Anxiety 28, 532-40. doi:10.1002/da.20847 


\section{Table 1}

Participant characteristics $(N=366)$

\begin{tabular}{|c|c|c|}
\hline Characteristic & \#/Mean & $\% /(S D)$ \\
\hline Diagnosed PTSD & 366 & $100 \%$ \\
\hline PSS-I score & 25.47 & 6.39 \\
\hline \multicolumn{3}{|l|}{ Gender } \\
\hline Men & 322 & 88.0 \\
\hline Women & 44 & 12.0 \\
\hline Age & $M=32.73$ & $(7.34)$ \\
\hline \multicolumn{3}{|l|}{ Marital status } \\
\hline Not married & 104 & 28.4 \\
\hline Married or cohabiting & 262 & 71.6 \\
\hline \multicolumn{3}{|l|}{ Education } \\
\hline High school & 117 & 32.0 \\
\hline College & 241 & 65.8 \\
\hline Postgraduate & 8 & 2.2 \\
\hline \multicolumn{3}{|l|}{ Ethnicity } \\
\hline Hispanic & 71 & 19.4 \\
\hline Non-Hispanic & 295 & 80.6 \\
\hline \multicolumn{3}{|l|}{ Race } \\
\hline Black & 86 & 23.5 \\
\hline White & 224 & 61.2 \\
\hline Asian & 3 & 0.8 \\
\hline Other & 53 & 14.5 \\
\hline \multicolumn{3}{|l|}{ Military service } \\
\hline Army & 363 & 99.2 \\
\hline Air Force & 3 & 0.8 \\
\hline \multicolumn{3}{|l|}{ Military grade $(n=363)$} \\
\hline \multicolumn{3}{|l|}{ Enlisted } \\
\hline E-1 to E-3 & 2 & 0.6 \\
\hline E-4 to E-6 & 285 & 78.5 \\
\hline E-7 to E-9 & 62 & 17.1 \\
\hline Warrant officer & 5 & 1.4 \\
\hline Officer & 9 & 2.5 \\
\hline \multicolumn{3}{|l|}{ Number of deployments } \\
\hline One & 108 & 29.5 \\
\hline Two & 110 & 30.1 \\
\hline Three & 94 & 25.7 \\
\hline Four or more & 54 & 14.8 \\
\hline
\end{tabular}


Note. E-1 to E-3, junior enlisted; E-4 to E-6, junior noncommissioned officers; E-7 to E-9, senior noncommissioned officers. 
Table 2

Means \& standard deviation of all study variables, and correlations between variables

\begin{tabular}{|c|c|c|c|c|c|c|c|c|c|}
\hline Measures & 1 & 2 & 3 & 4 & 5 & 6 & 7 & 8 & 9 \\
\hline 1. ISEL & - & & & & & & & & \\
\hline 2. WRAIR & $.207 * *$ & - & & & & & & & \\
\hline 3. RSES & $.307 * *$ & $.244 * *$ & - & & & & & & \\
\hline 4. PTCI_Negative self & $-.448 * *$ & $-.263 * *$ & $-.394 * *$ & - & & & & & \\
\hline 5. PTCI_Negative world & $-.282 * *$ & $-.221 * *$ & $-.145 * *$ & $.584 * *$ & - & & & & \\
\hline 6. PTCI_Self-blame & $-.215 * *$ & $-.161 * *$ & $-.176 * *$ & $.513 * *$ & $.294 * *$ & - & & & \\
\hline 7. PSS-I_Re-experiencing & -.034 & -.095 & .022 & $.227 * *$ & $.159 * *$ & $.152 * *$ & - & & \\
\hline 8. PSS-I_Avoidance & $-.418 * *$ & $-.181 * *$ & $-.226 * *$ & $.478 * *$ & $.250 * *$ & $.237 * *$ & $.277 * *$ & - & \\
\hline 9. PSS-I_Arousal & -.095 & -.087 & -.059 & $.263 * *$ & $.190 * *$ & $.118 *$ & $.322 * *$ & $.370 * *$ & - \\
\hline$M$ & 34.22 & 44.19 & 51.30 & 3.26 & 4.98 & 2.37 & 5.17 & 9.58 & 10.72 \\
\hline$S D$ & 7.80 & 13.20 & 16.10 & 1.19 & 1.23 & 1.27 & 2.75 & 3.38 & 2.47 \\
\hline
\end{tabular}

Note. ISEL=Interpersonal Support Evaluation List; WRAIR = The Walter Reed Army Institute of Research Military Vertical \& Horizontal Cohesion Scales; RSES = The Response to Stressful Events Scale; PTCINegative self $=$ The Posttraumatic Cognitions Inventory-Negative Cognitions About the Self subscale; PTCINegative world $=$ The Posttraumatic Cognitions Inventory-Negative Cognitions about the World subscale; PTCI-Self-blame $=$ The Posttraumatic Cognitions Inventory-Self-blame subscale; PSSI_Re-experiencing = PTSD Symptom Scale - Interview Version-Re-experiencing subscale; PSSI_Avoidance = PTSD Symptom Scale - Interview Version-Avoidance subscale; PSSI_Arousal = PTSD Symptom Scale - Interview VersionArousal subscale; $M=$ means; $S D=$ standard deviation.

** Correlation is significant at the 0.01 level (2-tailed).

* Correlation is significant at the 0.05 level (2-tailed). 


\section{Table 3}

Unstandardized and standardized regression coefficients and standard errors for all pathways of the final mediation model $(N=366)$

\begin{tabular}{|c|c|c|c|c|c|c|}
\hline Variable 1 & Variable 2 & $B$ & $S E$ & $\beta$ & se & $p$ \\
\hline Personal resources & Posttraumatic cognitions & -.197 & .024 & -.753 & .059 & $* * *$ \\
\hline Personal resources & PTSD & -.058 & .109 & -.096 & .198 & .591 \\
\hline Posttraumatic cognitions & PTSD & 1.197 & .369 & .512 & .170 & $* *$ \\
\hline Personal resources & Interpersonal support & $1^{\mathrm{a}}$ & & .581 & .032 & $* *$ \\
\hline Personal resources & Unit cohesion & 1.093 & .197 & .375 & .064 & $* * *$ \\
\hline Personal resources & Resilience & 1.909 & .261 & .536 & .057 & $* * *$ \\
\hline PTSD & PSSI_Re-experiencing & .365 & .059 & .367 & .053 & $* * *$ \\
\hline PTSD & PSSI_Avoidance & $1^{\mathrm{a}}$ & & .815 & .015 & $* * *$ \\
\hline PTSD & PSSI_Arousal & .409 & .053 & .458 & .045 & $* * *$ \\
\hline Posttraumatic cognitions & PTCI_Negative cognitions about self & $1^{\mathrm{a}}$ & & .996 & .032 & $* *$ \\
\hline Posttraumatic cognitions & PTCI_Negative cognitions about the world & .611 & .058 & .586 & .04 & $* * *$ \\
\hline Posttraumatic cognitions & PTCI_Self-blame & .552 & .059 & .515 & .044 & $* * *$ \\
\hline
\end{tabular}

Note. ${ }^{\text {a }}$ The path coefficients were constrained to 1. PTSD = posttraumatic stress disorder; PSSI_Re-experiencing = PTSD Symptom Scale - Interview Version-Re-experiencing subscale; PSSI_Avoidance = PTSD Symptom Scale - Interview Version-Avoidance subscale; PSSI_Arousal = PTSD Symptom Scale - Interview VersionArousal subscale; PTCI_Negative cognitions about self = Posttraumatic Cognitions Inventory-Negative Cognitions About the Self subscale; PTCI_Negative cognitions about the world = Posttraumatic Cognitions Inventory-Negative Cognitions About the World subscale; PTCI_Self-blame = Posttraumatic Cognitions Inventory-Self-Blame subscale.

$* * p<.01, * * * p<.001$. 


\section{Table 4}

Standardized direct, indirect, and total effects of variables PTSD and posttraumatic cognitions

\begin{tabular}{|c|c|c|c|c|c|c|c|c|c|}
\hline \multirow{2}{*}{ Variable } & \multicolumn{3}{|c|}{ Direct effect } & \multicolumn{3}{|c|}{ Indirect effect } & \multicolumn{3}{|c|}{ Total effect } \\
\hline & $\beta$ & $95 \% \mathrm{CI}$ & $p$ & $\beta$ & $95 \% \mathrm{CI}$ & $p$ & $\beta$ & $95 \% \mathrm{CI}$ & $p$ \\
\hline \multicolumn{10}{|l|}{ Effects on PTSD } \\
\hline Personal resources & -.096 & $-.146 / .347$ & .698 & -.386 & $-.748 /-.180$ & $* * *$ & -.481 & $-.651 /-.304$ & $* *$ \\
\hline Posttraumatic cognitions & .512 & $.299 / .882$ & $* *$ & 0 & - & - & .512 & $.299 / .882$ & $* *$ \\
\hline \multicolumn{10}{|c|}{ Effects on Posttraumatic cognitions } \\
\hline Personal resources & -.753 & $-.870 /-.641$ & $* *$ & 0 & - & - & -.753 & $-.870 /-.641$ & $* *$ \\
\hline
\end{tabular}

Note. $\mathrm{CI}=$ confidential interval. $\mathrm{PTSD}=$ posttraumatic stress disorder.

$* * p<.01, * * * p<.001$. 


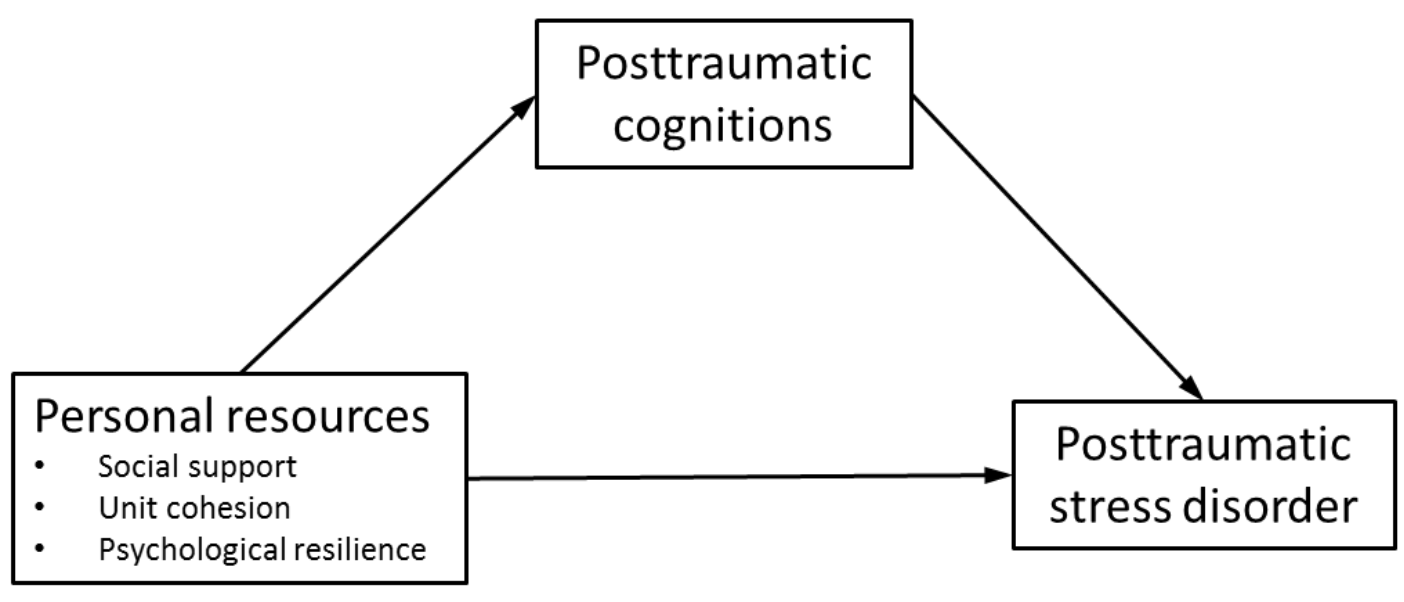

Fig. 1. Hypothesized model 


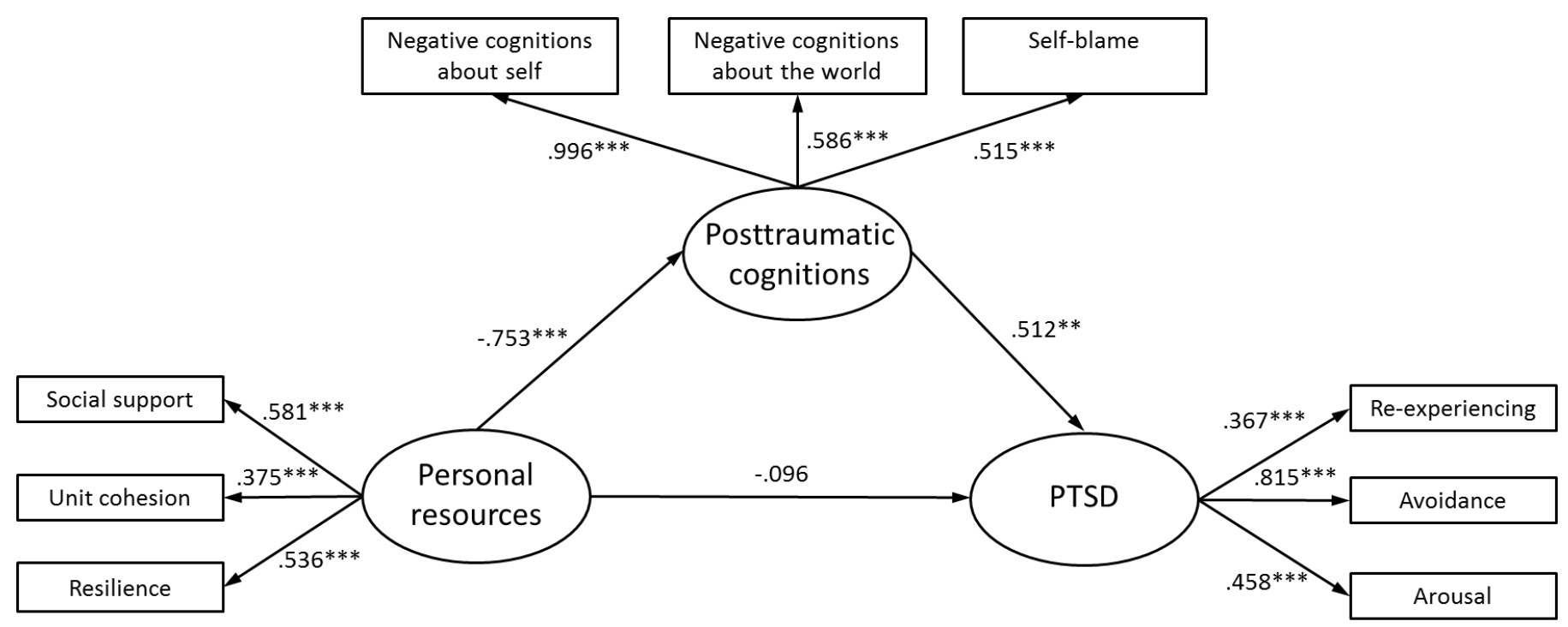

Fig. 2. Mediation model $(N=366)$, with standardized beta weights and significant level.

Fit statistics: $\chi^{2}(22)=16.344, p=.798 ; \chi^{2} / d f=.743 ; \mathrm{CFI}=1 ; \mathrm{RMSEA}=.000$.

PTSD = posttraumatic stress disorder.

$* * * p<.001 ; * * p<.01$ 


\section{Acknowledgments}

The views expressed in this article are solely those of the authors and do not reflect an

endorsement by the official policy of the U.S. Army, the Department of Defense, the Department of Veterans Affairs, or the U.S. Government. The authors express their sincerest appreciation to the study participants who shared their struggles with the research team. 